\title{
Types of refractive errors in northern Pakistan: a hospital-based survey
}

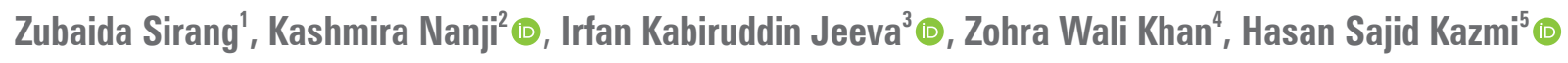 \\ 'Mater Misericordiae University Hospital, Dublin, Ireland \\ ${ }^{2}$ Department of Community Health Sciences, Aga Khan University Karachi, Pakistan \\ ${ }^{3}$ Ophthalmology Department, Aga Khan University Karachi, Pakistan \\ ${ }^{4}$ DHO Hospital, Booni Chitral, Pakistan \\ ${ }^{5}$ Ophthalmology Department, Ayub Teaching Hospital, Abbottabad, Pakistan
}

\begin{abstract}
BACKGROUND: The World Health Organisation (WHO) reports that about 314 million people are visually impaired worldwide, and in 153 million of them the impairment is due to uncorrected refractive errors. Hence, uncorrected refractive error is one of the leading causes of blindness around the globe. The aim of this study is to assess the prevalence and patterns of different types of refractive errors among the people attending the eye clinic in Northern Pakistan.

MATERIAL AND METHODS: A hospital-based retrospective audit was done on patients who presented to the Ophthalmology Outpatients Department of Ayub Medical Complex Abbottabad between $1^{\text {st }}$ June 2017 and $31^{\text {st }}$ July 2017. The data of 662 patients were analysed using IBM SPSS Statistics v. 22.0.

RESULTS: Refractive errors were found in 487 (73.5\%) of the total participants. The crude prevalence of myopia, hyperopia, and astigmatism was found to be $33.5 \%, 21.9 \%$, and $18.1 \%$, respectively. The refractive error status was found to be independent of gender $(p=0.075)$, but it varied among different age groups $(p=0.000)$.

CONCLUSION: Myopia seems to be the most common refractive error in northern Pakistan, followed by hyperopia. The results of our study can be useful for the planning of eye care services in our country so that we can achieve the goal of VISION 2020 with proper care and planning.
\end{abstract}

KEY WORDS: refractive error; myopia; hyperopia; astigmatism

Ophthalmol J 2019; Vol. 4, 86-91

\section{INTRODUCTION}

Refractive errors (myopia, hyperopia, and astigmatism) affect a large portion of the population worldwide. According to a WHO report about 314 million people are visually impaired worldwide, and in 153 million of them the impairment is due to uncorrected refractive errors [1].

The prevalence of different types of refractive errors varies considerably across different population and age groups. Many studies have been conducted to determine the prevalence of refractive errors in different parts of the world [2-8].

A study done in Bangladesh showed that the prevalence of myopia was $22.1 \%$ and that of hypermetropia $20.6 \%$ [4]. A study done in India showed that that the prevalence of myopia, hypermetropia, and astigmatism was $19.39 \%, 9.83 \%$, and $12.94 \%$, respectively, among the urban population of Southern India [5].

Studies done in Pakistan have focused mainly on the prevalence of refractive errors in chil- 
dren [9-13]. A study done in Karachi, Pakistan on 940 school-going children, found that the prevalence of refractive error was $8.9 \%$ and only $10.89 \%$ children had undergone a previous ophthalmic examination [13].

A national survey in Pakistan found the crude prevalence of myopia, hypermetropia, and astigmatism to be $36.5 \%, 27.1 \%$, and $37 \%$, respectively, in adults 30 years old and above [14].

Visual impairment from uncorrected refractive errors can have detrimental consequences including gaps in education, unemployment, financial challenges, and impaired quality of life [1]. Pakistan, being a developing country, is already facing a significant economic crisis. Uncorrected refractive errors can contribute to economic challenges by causing visual impairment amongst working-age persons.

National survey in Pakistan has found that refractive error was the commonest cause of moderate visual impairment followed by cataract [15]. Hence, it is important for health service providers to know about the magnitude and patterns of different types of refractive errors.

Epidemiologic research studies on the types and distributions of refractive errors will result in better planning of eye-care services and provision of corrective eyewear or other appropriate therapies. Therefore, we conducted the first hospital-based survey on the types and patterns of refractive errors among people attending the ophthalmology clinic in the District Abbottabad of Northern Pakistan.

\section{MATERIAL AND METHODS}

This was a hospital-based, retrospective study of the medical records of the patients presented to the Ophthalmology Outpatient Department, Ayub Teaching Hospital, Abbottabad, Pakistan from $1^{\text {st }}$ June to $31^{\text {st }}$ July 2017.

Ayub Teaching Hospital is one of the largest health care facilities in northern Pakistan. The medical records of all the patients who presented during the study period were retrieved. Patients were excluded if they were aphakic or pseudophakic in either eye or if details of refractive findings were missing. Information on the demographics and type of refractive error was taken. Records for right eye were taken for all the subjects except for anisometropia or antimetropia, for which the data for the worse eye (eye with higher refractive error) was analysed.

In this study, blindness was defined as a presenting visual acuity of $<3 / 60$ in the better eye.
Severe visual impairment was defined as visual acuity $<6 / 60$ to $\geq 3 / 60$, and moderate visual impairment was defined as visual acuity $<6 / 18$ to $\geq 6 / 60$ [16].

Anisometropia was defined as asymmetry in refractive error of at least $1 \mathrm{D}$ between the fellow eyes of an individual. Antimetropia was defined as an extreme subset of anisometropia in which one eye is myopic and the fellow eye is hyperopic.

Low myopia was defined as a spherical error of worse than $-0.5 \mathrm{D}$ but better than or equal to $-5 \mathrm{D}$, and high myopia as a spherical error of worse than -5 D. Low hypermetropia was defined as a spherical error of worse than $+0.5 \mathrm{D}$ but better than or equal to $+5 \mathrm{D}$, and high hypermetropia as worse than $+5 \mathrm{D}$. Spherical equivalents (SE) were calculated as half the cylinder plus the spherical component. Astigmatism (minus cylinder format) was defined as a cylindrical error worse than $0.75 \mathrm{D}$ [5-7].

Data were analysed using IBM SPSS Statistics v. 22.0.

Proportions were reported for all the categorical variables, the chi-square statistic was used to identify the factors associated with the refractive error, and a p-value $<0.05$ was considered as statistically significant.

\section{RESULTS}

Medical records of 1105 patients were retrieved. After excluding 443 patients for missing details and being pseudophakic/aphakic, data of 662 cases were analysed.

Of the total 662 participants, 327 (49.4) were males and 335 (50.6) were females, aged 2-80 years. The participants were divided into five age groups (Tab. I).

\section{PREVALENCE OF REFRACTIVE ERROR}

Of the total 662 participants, 487 (73.56\%) were found to have refractive error while 164 (24.8) were emmetrope. An almost equal proportion of refractive error was found among the male and female participants: $239(73.08 \%)$ males and $248(74.02 \%)$ females. Hence, the refractive error status was found to be independent of gender $(p=0.075)$, but it was found to vary among the different age groups $(\mathrm{p}<0.001)$ (Tab. II).

\section{MYOPIA}

Myopia was found in 222 participants, which represented $33.5 \%$ of the total participants. It was not found to vary with gender, but it was found to 


\begin{tabular}{|c|c|c|c|c|}
\hline Variables & Total $(n=662)$ & Myopia (\%) & Hyperopia (\%) & Astigmatism (\%) \\
\hline \multicolumn{5}{|c|}{ Age (years) } \\
\hline $2-19$ & $174(26.3)$ & $87(50)$ & 24 (13.79) & $31(17.81)$ \\
\hline 20-39 & 219 (33.1) & 70 (31.96) & 34 (15.52) & 48 (21.9) \\
\hline $40-59$ & $204(30.8)$ & 36 (17.64) & 72 (35.29) & $32(15.68)$ \\
\hline$\geq 60$ & $65(9.8)$ & $29(44.61)$ & $15(23.07)$ & $9(13.84)$ \\
\hline \multicolumn{5}{|l|}{ Gender } \\
\hline Males & 327 (49.4) & $102(31.19)$ & 72 (22.01) & 65 (19.87) \\
\hline Females & $335(50.6)$ & $120(35.82)$ & $73(21.79)$ & 55 (16.41) \\
\hline
\end{tabular}

\begin{tabular}{|c|c|c|c|}
\hline Variables & $\begin{array}{l}\text { Refractive error } n(\%) \\
(n=487)\end{array}$ & $\begin{array}{l}\text { Without refractive error (\%) } \\
\qquad(n=164)\end{array}$ & P-values \\
\hline \multicolumn{3}{|l|}{ Gender } & \multirow{3}{*}{$p=0.088$} \\
\hline Males & 239 (73.08) & $88(26.91)$ & \\
\hline Females & $248(74.02)$ & 87 (25.97) & \\
\hline \multicolumn{3}{|c|}{ Age (years) } & \multirow{5}{*}{$p<0.001$} \\
\hline $2-19$ & $142(81.60)$ & 32 (18.39) & \\
\hline 20-39 & $152(69.40)$ & 67 (30.59) & \\
\hline $40-59$ & $140(68.62)$ & 64 (31.37) & \\
\hline$\geq 60$ & $53(81.53)$ & $12(18.46)$ & \\
\hline
\end{tabular}

be more prevalent in the youngest and oldest age groups, having a U-shaped relationship with age (Tab. I).

\section{HYPERMETROPIA}

The prevalence of hyperopia was found to be $21.9 \%$ (Fig. 1).

It had no association with gender, but it was found to be more prevalent in the middle age group, having a reverse J-shaped relationship with age (Tab. I).

\section{ASTIGMATISM}

The crude prevalence of astigmatism was found to be $18.1 \%$ (Fig. 1).

The prevalence of astigmatism included those who had either myopia or hyperopia concurrent with astigmatism. It had no association with age or gender (Tab. I).

\section{PRESBYOPIA}

Presbyopia was found to be present in $482(72.80 \%)$ subjects. $239(73.08 \%)$ males and $243(72.53 \%)$ females were found to have presbyopia (Fig. 2).
It was found to be independent of gender $(\mathrm{p}=0.471)$.

\section{DISCUSSION}

To the best of our knowledge, this study provides the first hospital-based data on the prevalence and age/gender-specific distribution of different types of refractive errors in the District Abbottabad, Pakistan.

In our study, we found that the prevalence of refractive error among the people presenting to the eye clinic was $73.56 \%$, which is consistent with the national survey done in Pakistan [14].

In our study the prevalence of myopia was found to be $33.5 \%$, consistent with other studies done in Pakistan [14] and India but significantly higher than a national survey done in Bangladesh [4-5].

Our study reveals that there is a bimodal pattern of prevalence of myopia, which shows an initial decline in prevalence with age and then increases in the upper age group. This pattern is consistent with previous studies $[5,7,11]$.

The exact rationale for this observation is controversial. However, it has been well documented that 


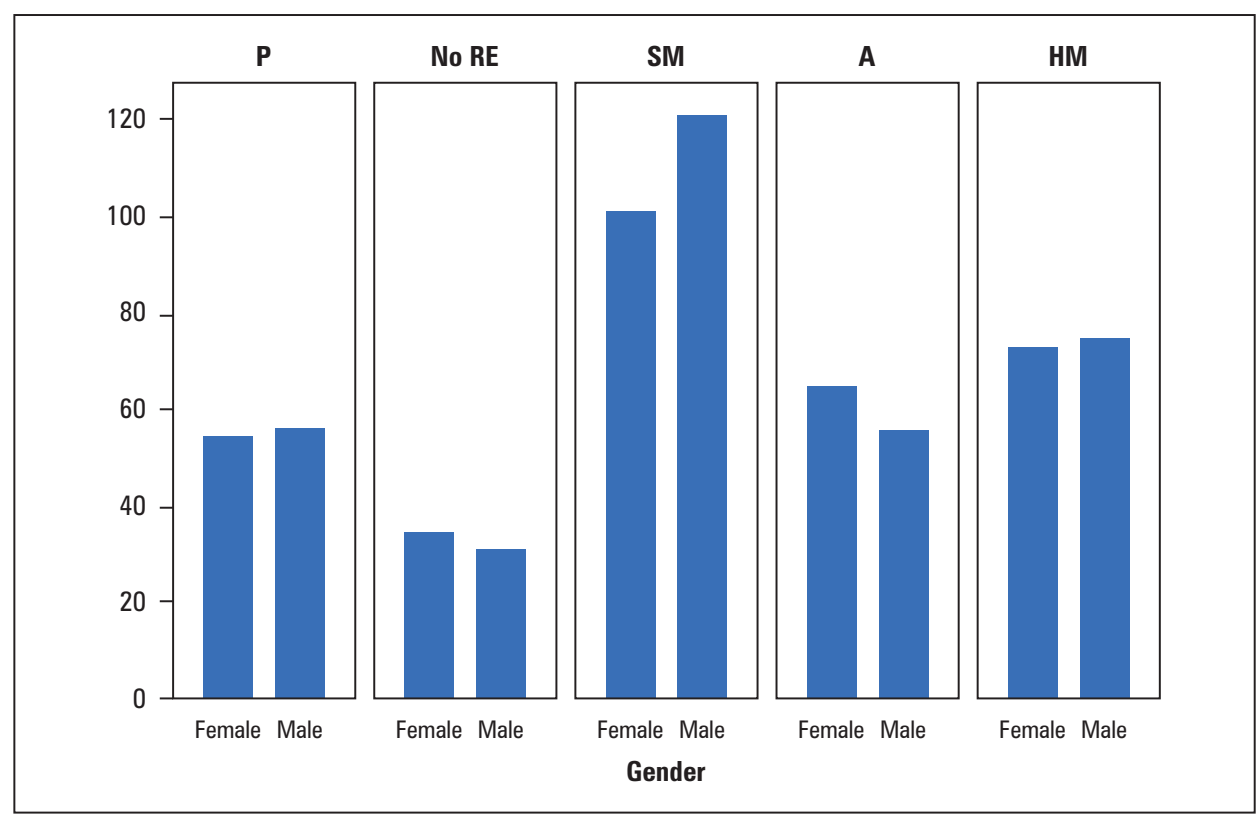

FIGURE 1. Prevalence of refractive errors among the study participants $(n=662)$

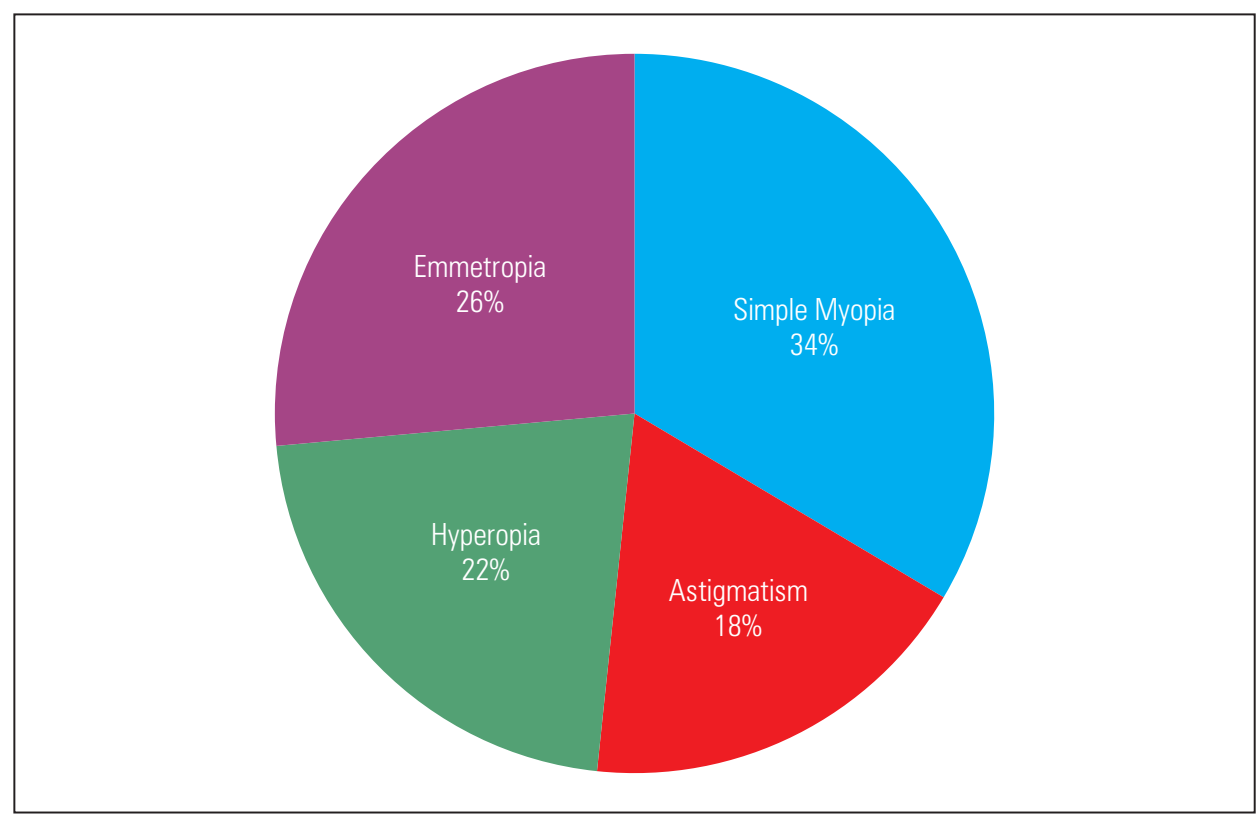

FIGURE 2. A bar chart representing the gender-specific prevalence of refractive error

the myopic shift in the old age group could be due to age-related lenticular changes $[3,5,7,14,16]$.

The reason for higher prevalence of myopia in the younger age group could be due to the cohort effect with time $[2,16]$. The high prevalence of myopia could also be due to the higher demand of close work (reading/writing, computer work/ video games) in the younger population, which gives support to the use/abuse theory of myopia $[3,5-7,14,16]$.
The prevalence of hypermetropia (22\%) is found to be slightly lower than the data of the national survey in Pakistan (27.1\%) [14] and is consistent with data from Bangladesh (20.6\%) [4]. It was found that there is an inverse J-shaped relationship between the prevalence of hyperopia and age: it was found to increase until the age of 59 years, and then it starts decreasing with increasing age. This phenomenon has been shown in previous studies, as well $[14,17]$. 
Environmental factors can be responsible for these phenomena in tropical countries [18]. It could also be attributed to age-related lenticular changes.

Another possible explanation could be due to a decrease in accommodation with age. Loss of accommodation can cause age-related increases in manifest hypermetropia and age-related decreases in apparent myopia, related to incomplete relaxation of accommodation during refraction, and such effects are less likely to be seen in individuals over 40 years of age [19].

The prevalence of astigmatism is found to be $18.1 \%$, which is very low compared to the data from the national survey done in Pakistan [14].

There could be unidentified reasons for this observable fact. The prevalence of refractive error status and refractive error types were not found to vary with gender.

This study has several potential limitations. Selection bias could have occurred due to it being a hospital-based, retrospective study. Another limitation of the study is that it was done in one of the districts of Pakistan, so the results might not be generalisable for the whole Pakistani population.

However, despite the aforementioned shortcomings of the study, the results of this study can be helpful for health care providers to have an overview of the types and pattern of refractive errors and to plan refractive error services in this part of the world. Our study will also serve as the initial step for conducting large-scale epidemiological studies on the same subject.

\section{CONCLUSION}

The results of this study show that un-corrected refractive error is a common problem in Pakistan, and further studies should be done in different parts of the country to meet the goal of VISION 2020 with proper knowledge and planning. Evidence from epidemiological studies will assist the WHO and International Agency for the Prevention of Blindness (IAPB). These agencies are working tirelessly to put uncorrected refractive error on the blindness prevention agenda and to develop strategies for the elimination of this easily avoidable cause of vision loss to achieve their goal of VISION 2020.

\section{ACKNOWLEDGEMENTS}

We are grateful to the management and staff of Ayub Teaching Hospital, Abbottabad for their support throughout the data collection phase.
None declared.

\section{CONFLICT OF INTEREST}

\section{AUTHORS' CONTRIBUTIONS}

Z.S. conceived and designed the analysis, collected the data, and wrote the paper. K.N. collected and entered the data and helped in writing the paper. I.J. helped in entering the data and writing the paper. ZWK helped in collecting and entering the data. H.S.K. helped in collecting and entering the data.

\section{REFERENCES}

1. Resnikoff $S$, Pascolini D, Mariotti SP, et al. Global magnitude of visual impairment caused by uncorrected refractive errors in 2004. Bull World Health Organ. 2008; 86(1): 63-70, doi: 10.2471/blt.07.041210, indexed in Pubmed: 18235892.

2. Vitale $S$, Ellwein $L$, Cotch MF, et al. Prevalence of refractive error in the United States, 1999-2004. Arch Ophthalmol. 2008; 126(8): 1111-1119, doi: 10.1001/archopht.126.8.1111, indexed in Pubmed: 18695106.

3. Angle J, Wissmann D. The epidemiology of myopia. Am J Epidemiol. 1980; 111(2): 220-228, doi: 10.1093/oxfordjournals.aje.a112889, indexed in Pubmed: 7355884

4. Bourne RRA, Dineen BP, Ali SM, et al. Prevalence of refractive error in Bangladeshi adults: results of the National Blindness and Low Vision Survey of Bangladesh. Ophthalmology. 2004; 111(6): 1150-1160, doi: 10.1016/j.ophtha.2003.09.046, indexed in Pubmed: 15177965.

5. Dandona $R$, Dandona $L$, Naduvilath $T J$, et al. Refractive errors in an urban population in Southern India: the Andhra Pradesh Eye Disease Study. Invest Ophthalmol Vis Sci. 1999; 40(12): 2810-2818, indexed in Pubmed: 10549640.

6. Tarczy-Hornoch K, Ying-Lai M, Varma R, et al. Los Angeles Latino Eye Study Group. Myopic refractive error in adult Latinos: the Los Angeles Latino Eye Study. Invest Ophthalmol Vis Sci. 2006; 47(5): 1845-1852, doi: 10.1167/iovs.05-1153, indexed in Pubmed: 16638990.

7. Wong TY, Foster PJ, Hee J, et al. Prevalence and risk factors for refractive errors in adult Chinese in Singapore. Invest Ophthalmol Vis Sci. 2000; 41(9): 2486-2494, indexed in Pubmed: 10937558.

8. Koroye-Egbe A, Ovenseri-Ogbomo G, Adio A. Refractive Error Status In Bayelsa State, Nigeria. J. Nigerian Optometric Asso. 2010; 16: 11-15.

9. Qayyum S. Refractive state of children in less than five years of age. J Surg Pakistan. 2006; 11: 73-75.

10. Awan HR, Ihsan T. Prevalence of visual impairment and eye diseases in Afghan refugees in Pakistan. East Mediter Health J. 1998; 4: 560-566.

11. Afghani T, Vine HA, Bhatti A, et al. Al-Shifa-Al-Noor (ASAN) refractive error study of one million school children. Pakistan J Ophthalmol. 2003; 19: 101-7.

12. Shaikh SP, Aziz TM. Pattern of eye diseases in children of 5-15 years at Bazzertaline Area (South Karachi) Pakistan. J Coll Physicians Surg Pak. 2005; 15(5): 291-294, doi: 05.2005/JCPSP.291294, indexed in Pubmed: 15907241.

13. Alam $\mathrm{H}$, Siddiqui $\mathrm{Ml}$, Jafri SI, et al. Prevalence of refractive error in school children of Karachi. J Pak Med Assoc. 2008; 58(6): 322-325, indexed in Pubmed: 18988392.

14. Shah SP, Jadoon MZ, Dineen $B$, et al. Refractive errors in the adult pakistani population: the national blindness and visual impairment survey. Ophthalmic Epidemiol. 2008; 15(3): 183-190, doi: 10.1080/09286580802105822, indexed in Pubmed: 18569814.

15. Dineen B, Bourne RRA, Jadoon Z, et al. Pakistan National Eye Survey Study Group. Causes of blindness and visual impairment in Pakistan. The Pakistan national blindness and visual impairment survey. $\mathrm{Br} \mathrm{J}$ Ophthalmol. 2007; 91(8): 1005-1010, doi: 10.1136/bjo.2006.108035, indexed in Pubmed: 17229806.

16. Wensor M, McCarty CA, Taylor HR. Prevalence and risk factors of myopia in Victoria, Australia. Arch Ophthalmol. 1999; 
117(5): 658-663, doi: 10.1001/archopht.117.5.658, indexed in Pubmed: 10326965.

17. Raju P, Ramesh SVe, Arvind H, et al. Prevalence of refractive errors in a rural South Indian population. Invest Ophthalmol Vis Sci. 2004; 45(12): 4268-4272, doi: 10.1167/iovs.04-0221, indexed in Pubmed: 15557431.
18. Saw SM. A synopsis of the prevalence rates and environmental risk factors for myopia. Clin Exp Optom. 2003; 86(5): 289-294, indexed in Pubmed: 14558850.

19. Curtin BJ. The myopias. Basic Science and Clinical Management. Harper and Row, Philadelphia 1985: 39-59. 